\title{
Rediscovery of old drugs: the forgotten case of dermorphin for postoperative pain and palliation
}

This article was published in the following Dove Press journal: Journal of Pain Research

\author{
Jan M Keppel Hesselink ${ }^{1,2}$ \\ Michael E Schatman ${ }^{3,4}$ \\ 'Department of Health, University of \\ Witten/Herdecke, Witten, Germany; \\ ${ }^{2}$ Institute for Neuropathic Pain, \\ Bosch en Duin, the Netherlands; \\ ${ }^{3}$ Department of Public Health and \\ Community Medicine, Tufts University \\ School of Medicine, Boston, MA, USA; \\ ${ }^{4}$ Research and Network Development, \\ Boston Pain Care, Waltham, MA, USA
}

Correspondence: Jan M Keppel Hesselink Department of Health, University of Witten/Herdecke, Witten, Germany Email jan@neuropathie.nu

\begin{abstract}
The repurposing of old drugs for new indications is becoming more accepted as a cost-efficient solution for complicated health problems. However, older drugs are often forgotten when they are not repositioned. This analysis makes a case for re-exploration of dermorphin for intrathecal use in postoperative pain and in a palliative context, with the goal of re-establishing this compound. Dermorphin was isolated from the skin of an Amazonian frog, characterized and identified as a bioactive heptapeptide by Vittorio Erspamer's research group in the early 1980s. It was traditionally called "Kambo" or "Sapo" by Amazon tribes and was used to improve their physical and psychic skills as hunters. Its structure is rather enigmatic, containing a D-amino acid, and its pharmacological activity in a number of assays was found to be quite impressive and superior to morphine. Moreover, it has been established as more selective and potent with long-lasting analgesia compared to morphine after intracerebroventricular administration in animal models. In 1985, the first clinical trial results of a randomized, placebo-controlled study in postoperative pain were reported, and dermorphin administered via the intrathecal route was again impressively superior over the placebo and the reference compound morphine. This milestone study was apparently minimally read by clinicians, as the study has never been referenced; only 15 pharmacological and review papers after 1985 mentioned the results, with not one being a clinical paper. The interest in dermorphin decreased after 1985, and the compound was never again introduced in the clinical setting. Considering the enormous pressure to find superior acting opioids, this is quite puzzling. We suggest new clinical studies to further evaluate the safety and efficacy of dermorphin, especially administered via the intrathecal route in postoperative pain or for palliative use in terminal patients.
\end{abstract}

Keywords: Kambo, Sapo, peptides, postoperative, analgesia, palliative, pain

\section{Introduction}

For a number of years, we have been quite interested in the repositioning of old drugs, especially subsequent to finding topical phenytoin, ketamine, baclofen, and loperamide effective in alleviating neuropathic pain. ${ }^{1}$ We have since concentrated on the repositioning of an old molecule, phenytoin, forgotten as an analgesic. ${ }^{2}$ We found phenytoin to be quite valuable for the treatment of localized peripheral neuropathic pain, for conditions including painful diabetic neuropathy, chemotherapy induced neuropathy, small fiber neuropathy, and chronic idiopathic axonal neuropathy. ${ }^{3}$ The clinical effects of this old molecule, first synthesized in the beginning of the 20th century, provoked us to search for other "forgotten molecules" useful in in the field of chronic pain. This was particularly relevant, as many pharmaceutical companies withdrew their research 
activities from this field over the past decade. In our investigation, the case of dermorphin arose once again.

The discovery, characterization, and isolation of a new opioid receptor agonist, dermorphin, in the dermal secrete of a specific Amazon frog (Phyllomedusa sauvagei) in 1981 by Montecucchi et al from the renowned Italian research group of Vittorio Erspamer (1909-1999), was groundbreaking. ${ }^{4}$ It was directly recognized by Erspamer and his colleagues that this heptapeptide possessed "exceptionally intense and long-lasting peripheral and central opiate-like actions." They, therefore, named the compound dermorphin, derived from the words "derm" and "morphine." The structure was elucidated as heptapeptide dermorphin (H-Tyr-D-Ala-PheGly-Tyr-Pro-Ser-NH2), and the position of a D-amino acid in this heptapeptide was quite remarkable. The group was captured by dermorphin and its peptide family, and in 1981 stated that it had become the object of nonstop work by them over the previous 2 years. ${ }^{5}$

In the early 1980 s, following the initial descriptions, many pharmacological papers on dermorphin were published. ${ }^{6-14}$ In 1985 the results of the initial milestone study in postoperative patients were published. The clinical findings were impressive, as dermorphin was superior to morphine in many ways. ${ }^{15}$ The interest in dermorphin peaked in 1985 (Figure 1) but has subsequently declined. In Google Scholar, only 15 papers are quoted which refer to this important 1985 clinical paper. Not one of those papers was written from a clinical point of view, with the study mentioned only in pharmacological and review papers, which strikes us as quite odd.

No further clinical papers on the effects of dermorphin in patients have been published subsequently. However, currently, dermorphin is still referred to as a gold standard for improved morphine, and as a potent and selective $\mu$-opioid receptor agonist. ${ }^{16}$

Although potentially superior to morphine, acting significantly longer than intrathecal morphine with significantly fewer patients requiring additional analgesics, no further

Results by year

1985: 41

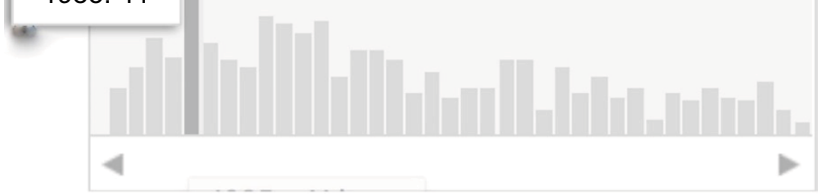

Figure I PubMed search using keyword "dermorphin" resulted in the first 10 hits in 1981, top year was 1985, and since then it shows a declining interest; $<600$ papers in PubMed can be found using this keyword. follow-up studies were published by any of the authors of the 1985 article, nor by anyone else. This analysis will review its pharmacological profile and discuss the clinical study results, thereby supporting our interest in reopening this forgotten chapter in opioid research and clarifying the potential value of dermorphin in clinical setups.

\section{Anthropological context}

Currently, one can easily find videos on the internet reporting on the preparation and administration of Kambo, which is rich in dermorphin and related peptides, and its immediate effects after administration. ${ }^{17,18}$ The earliest paper on Kambo use by Amazonian tribes was written by Gorman (1993), who visited the Matsés people of the Peruvian Amazon. ${ }^{19}$ He described the Matsés as a small, seminomadic, hunter-gatherer tribe who live in the remote jungle near the border between Peru and Brazil. The worldview of the Matsés is shamanistic; the earth is seen as the benevolent ti-ta (mother) who provides for all of their needs. Neighboring tribes claim that the Matsés "can move like the wind and talk with the animals" and that this tribe knows the jungle's secrets. Kambo (or Sapo) is one of these secrets. Phyllomedusa bicolor is known by the Matsés as "dow-kiet", and Gorman visited the area in order to collect specimens for researchers at both the American Museum of Natural History and the Fidia Research Institute for the Neurosciences in Rome, Italy. He was probably the first Western person experiencing the effects of Kambo. He described Kambo as presented on a piece of split bamboo, roughly the size and shape of a doctor's tongue depressor. The bamboo was covered with dried material, looking like aging varnish; it was referred to as "Sapo". The Indian scraped some material from the stick and mixed it with his own saliva, until it had the consistency and color of green mustard. After preparing the Kambo he burned small wounds on the inside of the forearm with a smoldering stick of wood. ${ }^{19}$ After each burn the blister was removed and some secretion of the frog was applied on the fresh wounds, with 2-5 burns generally created. The intense reaction which followed, due to the various peptides which were introduced directly into the lymphatic system, consisted of swelling of the lips and face, feelings of heat, accelerated heart rate, profuse sweating, stomach pain and violent vomiting, and involuntary urination and diarrhea. The duration of this reaction was noted to be relatively short, usually less than an hour. It was regarded by the administering people and the people who underwent the administration as a cleansing procedure. The Matsés used Sapo to become better hunters, with sharper sight and smell and the alleged ability to foresee game. In two papers, we 
described the experiences and reasons for Western people to follow Kambo ceremonies..$^{20,21}$

Since that first experience, many Western anthropologists and adventurers have traveled to the Amazon to experience Kambo. On YouTube, various videos demonstrate its administration and direct effects.

\section{Pharmacological profile}

Erspamer's research group, together with a colleague from the Farmitalia-Carlo Erba Research Laboratories, published the early pharmacological findings on dermorphin in 1981 in the British Journal of Pharmacology. ${ }^{22}$ With a priority date of 9-20-79, Farmitalia-Carlo Erba SpA patented many biologically active peptides selected from the group consisting of H-Tyr-ala-Phe-Gly-Tyr-Pro-Ser-NH2 and modifications thereof. ${ }^{23}$ In 1992, Erspamer noted that two other research groups also worked in the same field of synthesis of dermorphin analogs: the Ferrara group, with $>100$ analogs and $~ 20$ papers as of 1992, and a Japanese group that had synthesized $>20$ analogs. ${ }^{24}$

The analgesic effect of dermorphin, administered via the intracerebroventricular (ICV) route, was tested in rats in the classical hot plate and tail-flick test, and in mice via the intravenous (IV) route. Dermorphin ICV appeared to be a very potent analgesic in rats; the effective dose for $50 \%$ of the population (ED-50) in the tail-flick test was $23 \mathrm{pmol} /$ rat, the ED-50 of morphine was 752 times higher. ${ }^{22}$ In the hot plate test the ED-50 for dermorphin was $13.3 \mathrm{pmol} / \mathrm{rat}$, while for morphine it was $28.3 \mathrm{nmol} / \mathrm{rat}$, making dermorphin 2,170 times more potent than morphine in this test. The ICV application of $60 \mathrm{pmol}$ dermorphin/rat induced analgesia of $\sim 90$ minutes as determined by the tail-flick test, and $\sim 150$ minutes as determined by the hot plate test. Catalepsy occurred after more than doubling the dose (130 pmol/rat). The ED-50 of dermorphin in the IV mice model was 1.02 $\mu \mathrm{mol} / \mathrm{kg}(0.67-1.55)$, and that of morphine was found to be $11.3 \mu \mathrm{mol} / \mathrm{kg}(7.4-20.8) .{ }^{22}$ While analgesia was demonstrated in only $10 \%$ of all morphine-treated rats following 4 days of continuous infusion of morphine, for dermorphin it was observed in $65 \%$ of all rats, clearly indicating less tolerance compared with morphine. During withdrawal, less severe symptoms were seen in the dermorphin treated rats: morphinized rats demonstrated $>20$ shakes in 15 minutes, whereas dermorphin-treated animals never exceeded 10 shakes, with a mean of 6 shakes per 15 minutes. $^{22}$

As early as 1981, 90 dermorphin-like analogs were prepared at the Farmitalia-Carlo Erba Research Laboratories. In Farmitalia-Carlo Erba's first patent, it was stated that these compounds, based on the common structure and the remarkable D-amino acid residue, could act as analgesics, antipsychotics, and neuroendocrinologicals. Most of the patent covered the synthesis steps, and no details were provided apart from the fact that analgesic activity had been assessed in mice by the tail-pinch test following the administration of the peptides by a parenteral or oral route. When administered by IV route, the tested products displayed an analgesic effect at doses from 0.2 to $50 \mathrm{mg} / \mathrm{kg}$.

In 1982, it was demonstrated that dermorphin administered peripherally was unable to cross the blood-brain barrier, an important finding precluding oral use. ${ }^{25}$

The antinociceptive activity via the tail-pinch test of dermorphin and a number of analogs after subcutaneous administration in the rat was clearly inferior to the previous ICV route (ED-50: $0.83 \mathrm{mg} / \mathrm{kg}$ ). ${ }^{26}$ Comparing the ICV application of dermorphin with morphine, a dermorphin infusion of $200 \mathrm{ng} / \mathrm{h}$ was needed to obtain a degree of withdrawal equivalent to that produced by morphine at a much higher dose, that is, $10 \mu \mathrm{g} / \mathrm{h}$ per rat. ${ }^{27}$

By 1985, it was clear that dermorphin was much more potent and long-lasting compared with morphine following ICV administration, with indicators for less tolerance and withdrawal symptoms. That year, the first results of a clinical study were published, selecting a route of administration in line with the ICV animal experiments, that is, the intrathecal route. We feel this route is especially useful to further explore in the context of postoperative and, especially, palliative care due to ICV animal data, and based on the fact that high intrathecal morphine doses have limitations: decreases of $\mathrm{pH}$ in the liquor, limiting its analgesic effect, and the risk of developing granuloma at the tip of the catheter.

Interestingly, by conducting a search in Google Scholar, it was determined that no clinical researcher ever referenced the important 1985 milestone study, with only 15 pharmacological and review papers after 1985 mentioning the results. Sadly enough, the results were never disseminated in the clinical setting.

\section{Clinical study results}

Preliminary clinical studies were conducted prior to the clinicians of Italian hospitals in Aquila, Teramo, and Rome initiating their randomized controlled trial (RCT). ${ }^{15}$ In these open studies with an unspecified number of patients, $50 \%$ of patients treated with intrathecal dermorphin reported nausea or vomiting. In $10 \%$ of cases vomiting was persistent, but treatment with naloxone effectively relieved this symptom; however, the analgesic effect also was nullified. Pretreatment 
with domperidone was found to significantly lower the incidence of nausea or vomiting to $<20 \%$, which were no longer persistent in any case. These results led to the controlled RCT reported in $1985 .{ }^{15}$

This RCT included 3 arms and 2 comparator arms. One arm was the active control arm, and for this arm morphine chloride $500 \mu \mathrm{g}$ intrathecally+ intramuscular saline was administered. The second arm was administered with the test drug dermorphin $20 \mu \mathrm{g}$ intrathecally+ intramuscular saline, and the third arm was a placebo/control arm, consisting of pentazocine $30 \mathrm{mg}$ Intramuscularly plus puncture of the skin of the lumbar region (placebo).

The authors selected $500 \mu \mathrm{g}$ of morphine because higher doses have similar analgesic potency but may produce additional undesirable effects. Pain was evaluated by self-rating using the $10-\mathrm{cm}$ visual analog scale, with endpoints representing "no pain" to "maximum pain". Pain was evaluated every 4 hours during the first 48 hours, every 12 hours during the third, fourth and fifth postoperative days, and was also monitored when additional analgesics were requested. With all measurements, dermorphin was determined to have the highest analgesic effect compared to both other interventions; the pain scores on dermorphin did not exceed 1.5 at any measurement, while the morphine scores where double or more, and where highest between 8 hours and 48 hours after operation.

The mean duration of postoperative analgesia, measured as the interval between the administration of the study drug and the patient's request for additional analgesics, was significantly longer in the dermorphin group when compared to both the morphine and the control groups: control group 11 hours ( \pm 2 hours), morphine 34 hours ( \pm 2 hours), and dermorphin 43 hours ( \pm 2 hours). The percentage of patients requiring additional analgesics and the mean consumption of additional analgesics in the dermorphin group was significantly lower than in both the morphine and control groups. Only $22 \%$ of patients in the dermorphin group required extra analgesia, vs $58 \%$ and $88 \%$ in the morphine and control groups, respectively. Furthermore, the mean postoperative hospital stay was significantly shorter in the dermorphin group (5.6 days) and the morphine group (6.3 days) than in the control group (8.7 days).

Side effects reported were urinary retention, occurring in a higher percentage of patients on dermorphin (26\%) and morphine $(30 \%)$ compared to in the control group $(18 \%)$, and nauseas and vomiting also occurred in a higher percentage in the active arms compared to placebo $(22 \%$ and $18 \%$, respectively, vs $14 \%$ ). Postoperative complications in the three groups of patients were not significantly different, however, pulmonary infections were more frequent in the control group.

The authors pointed out that a single intrathecal injection of dermorphin could control the pain without the need for further analgesics in $80 \%$ of the patients. ${ }^{15}$

\section{Conclusion}

In our own work with the repositioning of phenytoin in a topical cream to treat peripheral neuropathic pain syndromes, it was observed that many colleagues initially reacted by expressing disbelief, referring to the fact that one cannot treat neuropathic pain via co-analgesics administered topically. Such judgements perhaps also played a role in the absence of acceptance of dermorphin. Erspamer himself noted that his team's initial findings were met with a great deal of skepticism among his peer group. Another potential reason for nonacceptance in the clinical setting may be that the results of the clinical study were published in a pharmacological journal that specializes in peptide research. A third reason is perhaps the most important to highlight. At that time (1980s), there was an emphasis on identifying improved opioids to deliver either orally or subcutaneously. The intrathecal route was not seen as a viable option for new compounds to develop. The clinical data presented and the support of the preclinical data related to the ICV administration of dermorphin in animal models, supporting its intrathecal use in postoperative analgesia and in palliative care situations. We feel this route is especially useful to further explore in the context of postoperative and, especially, palliative care, as suggested by the ICV data, and supported by the fact that high doses of intrathecal morphine have limitations: decreases of $\mathrm{pH}$ in the liquor, limiting its analgesic effect, and the risk of developing granuloma at the tip of the catheter. This route is perhaps also more appropriate Anno 2018 compared to 1985 , as the current intrathecal pumps are of much higher quality.

One specific topic of interest, related to possible limitations of the use of dermorphin in the setting suggested, will be the emergence of tolerance. That has been documented in some high-dose animal models, and therefore needs to be evaluated in a further clinical study. Furthermore, based on the data of the clinical study published in 1985, it seems that the side effect spectrum of dermorphin intrathecally administered was more benign compared to morphine, and perhaps higher effective doses can be used without giving rise to $\mathrm{pH}$ changes and catheter tip granulomata.

Since the presentation of the results of a pilot study and a well-controlled pivotal trial, no further clinical studies have been conducted with dermorphin intrathecal administration. 
We could not find any rational argument for the early abortion of this promising project, other than, perhaps, a sense that the profitability of such an endeavor would not be as great as that associated with mass-producing accepted, more traditional mu agonist agents. It seems that there is enough evidence to rediscover dermorphin, and hope that this article will present a new foundation for efforts toward such rediscovery.

\section{Disclosure}

Professor Keppel Hesselink is a patent holder of two patents related to the topical formulations of phenytoin in the treatment of neuropathic pain. Dr Schatman serves as a consultant to Kaleo Pharma. The authors report no other conflicts of interest in this work.

\section{References}

1. Keppel Hesselink JM, Kopsky DJ. Topical compounded analgesic treatment in neuropathic pain: 8 years of experience. J Pain Manage Med. 2017;3(2):128.

2. Keppel Hesselink JM. Phenytoin: repurposing an old molecule and patent strategies for neuropathic pain. J Clin Trials Pat. 2018;3:(1):33.

3. Kopsky DJ, Keppel Hesselink JM. Topical phenytoin for the treatment of neuropathic pain. J Pain Res. 2017;10:469-473.

4. Montecucchi PC, de Castiglione R, Piani S, Gozzini L, Erspamer V. Amino acid composition and sequence of dermorphin, a novel opiatelike peptide from the skin of Phyllomedusa sauvagei. Int J Pept Protein Res. 1981;17(3):275-283.

5. Erspamer V, Melchiorri P, Broccardo M, et al. The brain-gut-skin triangle: new peptides. Peptides. 1981;2(Suppl 2):7-16.

6. Erspamer V, Melchiorri P, Falconieri Erspamer G, Montecucchi PC, de Castiglione R. Phyllomedusa skin: a huge factory and store-house of a variety of active peptides. Peptides. 1985;6:7-12.

7. Montecucchi PC, de Castiglione R, Erspamer V. Identification of dermorphin and Hyp6-dermorphin in skin extracts of the Brazilian frog Phyllomedusa rhodei. Int J Pept Protein Res. 1981;17(3):316-321.

8. Buffa R, Solcia E, Magnoni E, Rindi G, Negri L, Melchiorri P. Immunohistochemical demonstration of a dermorphin-like peptide in the rat brain. Histochemistry. 1982;76(2):273-276.

9. Negri L, Melchiorri P, Erspamer GF, Erspamer V. Radioimmunoassay of dermorphin-like peptides in mammalian and non-mammalian tissues. Peptides. 1981;2(Suppl 2):45-49.

10. Salvadori S, Sarto G, Tomatis R. Synthesis and pharmacological activity of dermorphin and its N-terminal sequences. Int J Pept Protein Res. 1982;19(5):536-542.
11. Sasaki Y, Matsui M, Taguchi M, et al. D-Arg2-dermorphin tetrapeptide analogs: a potent and long-lasting analgesic activity after subcutaneous administration. Biochem Biophys Res Commun. 1984;120(1):214-218.

12. Improta G, Broccardo M, Lisi A, Melchiorri P. Neural regulation of gastric acid secretion in rats: influence of dermorphin. Regul Pept. 1982;3(3-4):251-256.

13. Braga PC, Tiengo M, Biella G, dall'oglio G, Fraschini F. Dermorphin, a new peptide from amphibian skin, inhibits the nociceptive thalamic neurons firing rate evoked by noxious stimuli. Neurosci Lett. 1984;52(1-2):165-169.

14. Giagnoni G, Parolaro D, Casiraghi L, et al. Dermorphin interaction with peripheral opioid receptors. Neuropeptides. 1984;5(1-3):157-160.

15. Basso N, Marcelli M, Ginaldi A, de Marco M. Intrathecal dermorphine in postoperative analgesia. Peptides. 1985;6(Suppl 3):177-179.

16. Willemse T, Eiselt E, Hollanders K, et al. Chemical space screening around Phe 3 in opioid peptides: modulating $\mu$ versus $\delta$ agonism by Suzuki-Miyaura cross-couplings. Bioorg Med Chem Lett. 2018;28(13):2320-2323.

17. Sapo [Webpage on the Internet]. Available from: https:/www.youtube. com/watch?v=eQHaqEAZWqE. Accessed August 26, 2018.

18. Catching Sapo and Kambo ceremony in the Jungle of Peru 2018 [Webpage on the Internet]. Available from: https://www.youtube.com/ watch?v=Ox8RYDIYISA. Accessed August 26, 2018.

19. Gorman P. Making magic. Omni. 1993;15:65-67.

20. Keppel hesselink JM. Kambô: A shamanistic ritual arriving in the Westphenomenology, risks and opportunities. Int J Psychol Psychoanal, submitted for review.

21. Keppel Hesselink JM. Kambô: a Shamanic Medicine - Personal Testimonies. Juniper Online J Case Studies, submitted for review.

22. Broccardo M, Erspamer V, Falconieri Erspamer G, et al. Pharmacological data on dermorphins, a new class of potent opioid peptides from amphibian skin. Br J Pharmacol. 1981;73(3):625-631.

23. de Castiglione R, Faoro F, Perseo G, et al. Biologically active peptides. Patent US4350627A, Priority date 1979-09-20. Original Assignee Farmitalia Carlo Erba SpA.

24. Erspamer V. The opioid peptides of the amphibian skin. Int $J$ Dev Neurosci. 1992;10(1):3-30.

25. Negri L, Improta G. Preliminary data on dermorphin distribution and metabolism. In: $21^{\text {st }}$ Congress of the Italian Pharmacological Society; June 2-5, 1982; Naples, Italy. Abstract. p. 167; quoted in Parolaro D, Sala M, Crema G, Spazzi L et al. Central and peripheral components of dermorphin's effect on rat intestinal propulsion in comparison to morphine. Peptides 1983;4(1):55-8.

26. Rossi A, di Salle E, Briatico G, Arcari G, de Castiglione R, Perseo G. Antinociceptive, prolactin releasing and intestinal motility inhibiting activities of dermorphin and analogues after subcutaneous administration in the rat. Peptides. 1983;4(4):577-580.

27. Broccardo M, Improta G, Negri L, Melchiorri P. Tolerance and physical dependence induced by dermorphin in rats. Eur J Pharmacol. 1985;110(1):55-61.
Journal of Pain Research

\section{Publish your work in this journal}

The Journal of Pain Research is an international, peer reviewed, open access, online journal that welcomes laboratory and clinical findings in the fields of pain research and the prevention and management of pain. Original research, reviews, symposium reports, hypothesis formation and commentaries are all considered for publication.

\section{Dovepress}

The manuscript management system is completely online and includes a very quick and fair peer-review system, which is all easy to use. Visit http://www.dovepress.com/testimonials.php to read real quotes from published authors. 